\title{
DNA implementation of addition in which the input strands are separate from the operator strands
}

\author{
Bernard Yurke*, Allen P. Mills Jr., Siu Lai Cheng \\ Bell Laboratories, Lucent Technologies, IC363, 600 Mountain Avenue, Murray Hill, NJ 07974, USA
}

\begin{abstract}
A DNA representation of Boolean logic for which the input strands are separate from the operator strands is described and used to construct a two-bit DNA adder. The successful operation of the adder for several test inputs demonstrates that digital molecular computation with a complexity of order 30 gates is feasible. (C) 1999 Elsevier Science Ireland Ltd. All rights reserved.
\end{abstract}

Keywords: DNA computing; DNA adder; Boolean logic

DNA computing has recently attracted considerable attention (Adleman 1994; Lipton 1995; Guarnieri et al., 1996; Ouyang et al., 1997). Much of the interest has arisen from the hope that the massive parallelism that DNA computing potentially offers may make it competitive with electronic computing. In this regard, much work has focused on developing DNA algorithms for solving NP complete problems. We point out, however, that it is likely that situations will arise where one would like the ability to carry out computations with DNA for which competitiveness with electronic computation is not an issue. For example, the implementation of logic functions in DNA may aid in the assembly of complex structures from DNA. Strands of DNA capable of making logical decisions could conceivably also

\footnotetext{
* Corresponding author. Tel.: + 1-908-5824961; fax: + 1908-5823260.

E-mail address: yurke@lucent.com (B. Yurke)
}

serve as components of smart drug delivery systems or gene manipulating systems. From this point of view various ways of giving DNA computing functionality should be explored regardless of whether such a technology could ever compete with electronic computation.

Here we describe a way of carrying out Boolean logic functions using hybridization and ligation, two of the DNA chemical operations that Adleman (1994) and Lipton (1995) used in their pioneering works. We use this method to implement a two-bit DNA adder which we have constructed and successfully tested. The adder differs from the ingenious adder devised by Guarnieri et al. (1996) in that the inputs and the addition machinery consist of separate strands of DNA. Such separation of the computation machinery, consisting of operator strands, from the inputs would be essential for applications in self-assembly and smart drug delivery where the environment provides the inputs on which decisions are to be based. 
Following Lipton (1995), we note that any Boolean function $F\left(X_{1}, X_{2} \ldots X_{n}\right)$ can be written in the form

$$
F\left(X_{1}, X_{2}, \ldots X_{n}\right)=C_{1} \vee \ldots C_{2} \vee \ldots C_{m}
$$

where $\vee$ denotes the OR operation and $C_{i}$ is a clause of the form

$C_{i}=Y_{i 1} \wedge Y_{i 2} \wedge \ldots Y_{i k}$.

Here $\wedge$ denotes the AND operation and

$$
Y_{i j} \in\left\{X_{1}, \bar{X}_{1}, X_{2}, \bar{X}_{2}, \ldots X_{n}, \bar{X}_{n}\right\}
$$

where the bar denotes negation. From this observation it is evident that, if one implements negation at the input, AND and OR gates suffice to construct any Boolean function. Thus, we represent each Boolean variable $X_{i}$ by two distinct noncomplementary strands of DNA $x_{i}$ and $\bar{x}_{i}$ where the presence of $x_{i}$ indicates that $X_{i}$ is true and the presence of $\bar{x}_{i}$ indicates that $X_{i}$ is false. Hybridization of the input strands with operator strands, followed by ligation and denaturing, is used to assemble the structures $f$ if $F$ is true and structures $\bar{f}$ if $F$ is false. The value of $F$ is thus not based on whether or not a structure $f$ is present but on whether $f$ is present or $\bar{f}$ is present. This facilitates insuring that there is an output above background regardless of whether $F$ is true or false.

Before considering the general case, consider the implementation of the function

$$
F=X_{1} \wedge X_{2}
$$

on a hybridization plate so that one spot, at location 1, becomes fluorescent when $F$ is true and another spot, at location 2, becomes fluorescent when $F$ is false. Strands of DNA having a sequence $p$ are covalently attached at spot 1 . Strands of DNA having a different sequence $\bar{p}$, not complementary to $p$, are covalently attached at spot 2. Present in solution are fluorescent dye molecules attached to a DNA strand labeled $u$. Consider the operator strand $c p-c x_{1}-c x_{2}-c u$ where $c p, c x_{1}, c x_{2}$, and $c u$ denote the strands complementary to $p, x_{1}, x_{2}$, and $u$, respectively. This operator strand will hybridize with the DNA attached at spot 1 and with the fluorescently labeled DNA strands in solution. If $x_{1}$ and $x_{2}$ are both present these strands will also hybridize with the operator strand. In the presence of DNA ligase a continuous strand of DNA, $f=p-x_{1}-$ $x_{2}-u$, will be formed covalently linking the fluorescent dye at one end and the substrate at the other end. Upon denaturing and washing, spot 1 will fluoresce only if $x_{1}$ and $x_{2}$ had been present, thus representing that part of the Boolean function Eq. (4) for which $F$ is true. To implement that part of $F$ for which it is false we note that from DeMorgan's theorem

$\bar{F}=\bar{X}_{1} \vee \bar{X}_{2}$.

Consider the operator strands $\bar{f}_{1}=c \bar{p}-c \bar{x}_{1}-c u$ and $\bar{f}_{2}=c \bar{p}-c \bar{x}_{2}-u$. Both of these operator strands will hybridize with the DNA covalently attached to spot 2 and with the fluorescently labeled strand $u$. Thus, in the presence of ligase, if either $\bar{x}_{1}$ or $\bar{x}_{2}$ is present DNA strands will be formed covalently linked to the substrate at one end and with a dye molecule covalently attached at the other end. Upon denaturing and washing, spot 2 will fluoresce only if $\bar{x}_{1}$ or $\bar{x}_{2}$ had been present. Thus, with the prepared hybridization plate and the operator strands $f=c p-c x_{1}-$ $c x_{2}-c u, \bar{f}_{1}=c \bar{p}-c \bar{x}_{1}-c u$ and $\bar{f}_{2}=c \bar{p}-c \bar{x}_{2}-u$ one has a full implementation of the function $F$, Eq. (4), where a separate spot becomes fluorescent depending on whether $F$ is true or false.

Note that Eqs. (4) and (5) both have the form Eq. (1). Our implementation of Eq. (4) can be written as

$f=x_{1} \wedge x_{2}$

$\bar{f}=\bar{x}_{1} \vee \bar{x}_{2}$.

In effect we have implemented both an AND and an $O R$ function. AND functions are carried out by joining two input strands through ligation mediated by an operator strand that aligns the two input strands end to end. The $O R$ function is achieved by assembling more than one clause at a given location on a hybridization plate. Although multi-input clauses could be constructed, to keep the length of the required oligonucleotides small or to reduce the number of different nucleotides required, the clauses can be assembled by joining AND operators together with linker DNA strands. For example, the operation 
$f=x_{1} \wedge x_{2} \wedge y_{1} \wedge y_{2}$

could be implemented using the following operator strands: $c p-c x_{1}-c x_{2}-c l_{1}$ and $c l_{2}-c y_{1}-$ $c y_{2}-c u$ and the linker strand $l_{1}-l_{2}$. If $x_{1}, x_{2}, y_{1}$, and $y_{2}$ are present, ligation will produce the strand $f=p-x_{1}-x_{2}-l_{1}-l_{2}-y_{1}-y_{2}-u$ covalently linked to the substrate at one end and having a fluorescent dye label at the other end.

Using the notation of Eq. (8), the addition of two binary numbers $x$ and $y$ to give $z=x+y$ is accomplished by the algorithm:

$z_{0}=\left(x_{0} \wedge \bar{y}_{0}\right) \vee\left(\bar{x}_{0} \wedge y_{0}\right)$

$\bar{z}_{0}=\left(\bar{x}_{0} \wedge \bar{y}_{0}\right) \vee\left(x_{0} \wedge y_{0}\right)$

$c_{1}=x_{0} \wedge y_{0}$

$\bar{c}_{1}=\bar{x}_{0} \vee \bar{y}_{0}$

$z_{i}=\left(x_{i} \wedge \bar{y}_{i} \wedge \bar{c}_{i}\right) \vee\left(\bar{x}_{i} \wedge y_{i} \wedge \bar{c}_{i}\right) \vee\left(x_{i} \wedge y_{i} \wedge c_{i}\right)$

$\bar{z}_{i}=\left(\bar{x}_{i} \wedge \bar{y}_{i} \wedge \bar{c}_{i}\right) \vee\left(x_{i} \wedge y_{i} \wedge \bar{c}_{i}\right) \vee\left(\bar{x}_{i} \wedge y_{i} \wedge c_{i}\right)$

$$
\vee\left(x_{i} \wedge \bar{y}_{i} \wedge c_{i}\right)
$$

$c_{i+1}=\left(x_{i} \wedge y_{i}\right) \vee\left(y_{i} \wedge c_{i}\right) \vee\left(x_{i} \wedge c_{i}\right)$

$\bar{c}_{i+1}=\left(\bar{x}_{i} \wedge \bar{y}_{i}\right) \vee\left(\bar{x}_{i} \wedge \bar{c}_{i}\right) \vee\left(\bar{y}_{i} \wedge \bar{c}_{i}\right)$

where $c_{i}$ is the $i$-th carry bit and $i=0$ refers to the least significant bit, for which the carry bit is zero, $\left(c_{0}=0, \bar{c}_{0}=1\right)$. Eqs. (9)-(12) constitute those of a half adder since there are no carry inputs. Eqs. (13)-(16) constitute those of a full adder. By counting the number of ANDs and ORs in these equations, one finds that the implementation of two-bit addition according to these equations would require more than 30 gates even if three input AND gates are employed. A DNA adder of this level of complexity is demonstrated here.

How the operation of Eqs. (9) and (10) is implemented in DNA is illustrated in Fig. 1. The DNA strands $z 0 n$ and $z 0$ are respectively covalently attached to spots $z 0 n$ and $z 0$ of the hybridization plate. The operator strands $\mathrm{ZON}_{-} \mathrm{XO}_{-} \mathrm{YO} \mathrm{O}_{-} \mathrm{U}$ and $\mathrm{ZON} \mathrm{XON}_{-} \mathrm{YON} \mathrm{X}_{-} \mathrm{U}$ hybridize to the $z O n$ strands and to the dye labeled strands u. Similarly, the operator strands $\mathrm{ZO}_{-}$ $\mathrm{XO}_{-} \mathrm{YON}_{-} \mathrm{U}$ and $\mathrm{ZO} \mathrm{O}_{-} \mathrm{XON} \mathrm{N}_{-} \mathrm{YO} \mathrm{O}_{-} \mathrm{U}$ hybridize with the zo strands and with $u$. To perform the computation $1+0$, the input strands $\mathrm{x} 0$ and $\mathrm{y} 0 \mathrm{n}$ are added to the solution in which the hybridization plate is emersed. These hybridize with the operator strands as shown in Fig. 1(a). Fig. 1(b) shows the DNA that remains after ligation, denaturing, and washing. Only the spot $z 0$ has fluorescent dye attached indicating that the result of adding 1 and 0 is 1 .

Although to simplify the discussion we have described the method of implementing Boolean logic in terms of assembly on a hybridization plate, there are other ways this logic can be implemented. In particular, the computation done at a given spot on a hybridization plate could instead be done in a given test tube. The DNA
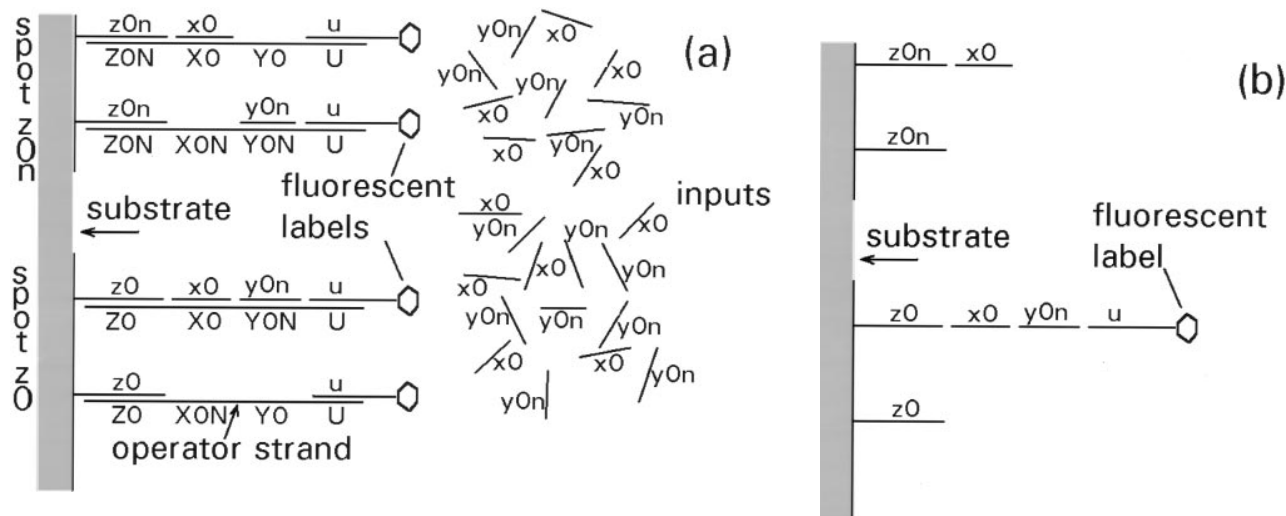

Fig. 1. Illustration of how Eqs. (9) and (10) can be implemented in DNA. (a) illustrates how the operator strands, input strands, and fluorescent dye labeled strands assemble through hybridization. (b) illustrates the DNA that remains attached to the hybridization plate after ligation, denaturing, and washing. For the case illustrated spot $z 0$ will fluoresce while spot $z 0 n$ will not. 
that would be attached to a solid support could now be labeled with fluorescent dye of a different color than that used for $u$. Readout can then be accomplished using gel electrophoresis under denaturing conditions. The successfully completed computations would be those which produce bands fluorescing at the two dye colors. Compartmentalization into test tubes also allows one to add to a particular test tube only those operator strands that will actually be used in the computation. It is this implementation in which a separate test tube is used to compute each output bit that we have tested experimentally.

For the experimental implementation of a twobit adder, we selected a set of decamers to represent the variables in our algorithm. Each member of the set was chosen to have between four and six A/T's each, to have no more than three in a row of either $\mathrm{A} / \mathrm{T}$ 's or $\mathrm{C} / \mathrm{G}$ 's and to have no significant match with its complement or with any other member of the set or its complement for shifts of up to \pm 4 bases. The first member of the set was taken to be 5' TGCAGTCTCG 3'. Giving a $\mathrm{G} / \mathrm{C}$ match a weight of 6 and an $\mathrm{A} / \mathrm{T}$ match a weight of 4 , a significant match was taken to be a sum of the weights of the matching bases greater than 24 , i.e., $6 \mathrm{~A} / \mathrm{T}$ matches or $4 \mathrm{G} / \mathrm{C}$ matches, etc. We were able to find 27 strands other than the starting strand that satisfied these conditions.

The strands used in constructing the adder are given in Table 1. In the notation employed, upper case symbols are used for the operator strands. The upper and lower case letter n's are used for strings representing a logical not value (zero value) for a variable. The $\mathrm{px}^{\prime} \mathrm{s}, \mathrm{py}^{\prime} \mathrm{s}$, and $\mathrm{z}^{\prime} \mathrm{s}$ are readout oligomers. Although the sequences were designed for use with hybridization plates in which the oligonucleotides 17-24 for the input readout and 11-16 for the output readout would each be covalently attached at the $3^{\prime}$ end to the substrate, for the experiments reported here hybridization was performed in solution and gel electrophoresis under denaturing conditions was used to read the results of the computation. To further facilitate the identification of the output strands, strands 17-24 and 11-16 were fluorescently labeled with Texas-red at the $3^{\prime}$ end. The indicator strand 25 is fluorescently labeled with fluorescein at the $5^{\prime}$ end. The output strands thus constitute strands that are fluorescent both in the green and in the red when illuminated with white light, and thus appear yellow. Bands containing incomplete by-products of the computation appear green or red under the same illumination conditions unless the band happens by chance to be a nearly equal mixture of Texas-red and fluorescein labeled DNA strands of equal length.

The methods used for the addition experiments are described in Section 1. A typical experiment is completed in $\sim 3 \mathrm{~h}$. About $2 \mathrm{~h}$ are taken up in preparing the contents of each vial and the incubation with kinase and ligase. A little over $1 \mathrm{~h}$ is used to perform gel electrophoresis. Fig. 2 shows the results for the half adder whose functioning was verified for all four possible inputs. Each photo displays four pairs of lanes produced during gel electrophoresis. The first pair of lanes reads out the input bit $x 0$. The second pair of lanes reads out the input bit $y 0$. The third pair of lanes reads out the carry bit. The fourth pair of lanes reads out the least significant bit of the sum. Let $A$ denote the Boolean variable that is being read out by a pair of lanes. If a bright yellow band appears higher in the left column than in the right column one has $A=0$. Conversely, if a bright yellow band appears higher in the right column than in the left one has $A=1$. The photographs on the left were taken under blue light illumination with an ethidium bromide filter in front of the camera. From the red bands appearing in these photographs it is evident that the blue light is able to excite Texas-red fluorescence. The photographs on the right were taken under green light illumination with a red filter in front of the camera. The green bands are absent due to the efficient blocking of green light by the red filter. The readout bands for the inputs $x 0$ and $x 1$ consist of strands of DNA 46 nucleotides long. The strand $\mathrm{px} 0-\mathrm{x} 0-\mathrm{u}$ formed when $x 0$ is true is a typical example of these strands. The $z 1$ output strand when the $z 1$ is true is 53 nucleotides long. The strand formed for the case of the $1+1$ addition, $\mathrm{c} 1 \mathrm{a}-\mathrm{c} 1 \mathrm{~b}-\mathrm{x} 0-\mathrm{y} 0-\mathrm{u}$, is an example of this. When the $z 1$ output is false the output strand is 43 nucleotides long. An example of such a strand is $c 1 a n-c 1 b n-y 0 n-u$. The readout 
Table 1

Listing of oligonucleotide sequences

\begin{tabular}{|c|c|c|}
\hline & Name & Sequence \\
\hline 1 & x0 & AGTGTATGAG \\
\hline 2 & $\mathrm{x} 0 \mathrm{n}$ & CCATACCAGC \\
\hline 3 & $\mathrm{x} 1$ & GTGCTTCGTT \\
\hline 4 & $\mathrm{x} 1 \mathrm{n}$ & TGATCCAAGA \\
\hline 5 & y0 & GTCACCTATG \\
\hline 6 & $\mathrm{x} 0 \mathrm{n}$ & TATCAGGTTG \\
\hline 7 & y1 & TCGCTATGAA \\
\hline 8 & y $1 \mathrm{n}$ & AGCATCTAAC \\
\hline 9 & $\mathrm{c} 1 \mathrm{a}_{-} \mathrm{c} 1 \mathrm{~b}$ & GAACAACACTTACTCACAAC \\
\hline 10 & clan_clbn & AATGTGTACCAAAGCCATAG \\
\hline 11 & zo & CTTGATCTCCAGTGCAGTCTCGA \\
\hline 12 & $\mathrm{z} 0 \mathrm{n}$ & CGGAAGTAGTAGTGCAGTCTCGA \\
\hline 13 & z1 & CGGATACTTAAGTGCAGTCTCGA \\
\hline 14 & $\mathrm{z} 1 \mathrm{n}$ & TTTCCACTAGAGTGCAGTCTCGA \\
\hline 15 & $\mathrm{z} 2$ & GATCTGTTGAAGTGCAGTCTCGA \\
\hline 16 & $z 2 n$ & GCCTATCCTAAGTGCAGTCTCGA \\
\hline 17 & $\mathrm{p} \times 0$ & GAATGAAAGCAGTGCAGTCTCGA \\
\hline 18 & $\mathrm{px} 0 \mathrm{n}$ & CACAGTAAGTAGTGCAGTCTCGA \\
\hline 19 & $\mathrm{p} \times 1$ & CAATCGTCAAAGTGCAGTCTCGA \\
\hline 20 & $\mathrm{p} \times 1 \mathrm{n}$ & GATCGTACTTAGTGCAGTCTCGA \\
\hline 21 & py 0 & TGAAGGGTAAAGTGCAGTCTCGA \\
\hline 22 & pyon & TAGAAACGTGAGTGCAGTCTCGA \\
\hline 23 & py 1 & AAGAGCAGAAAGTGCAGTCTCGA \\
\hline 24 & py $1 n$ & TTCCGACATAAGTGCAGTCTCGA \\
\hline 25 & $\mathrm{u}$ & $\begin{array}{l}\text { AAATGTCCTTGTC (5'-fluores- } \\
\text { cein-labeled) }\end{array}$ \\
\hline 26 & $\mathrm{PXO}_{-} \mathrm{XO}_{-} \mathrm{U}$ & $\begin{array}{l}\text { GCTTTCATTCCTCATACACTGA- } \\
\text { CAAGGACA }\end{array}$ \\
\hline 27 & $\mathrm{PXON} \_\mathrm{XON} \_\mathrm{U}$ & $\begin{array}{l}\text { ACTTACTGTGGCTGGTATGGGA- } \\
\text { CAAGGACA }\end{array}$ \\
\hline 28 & $\mathrm{PX} 1_{-} \mathrm{X} 1_{-} \mathrm{U}$ & $\begin{array}{l}\text { TTGACGATTGAACGAAGCACGA- } \\
\text { CAAGGACA }\end{array}$ \\
\hline 29 & $\mathrm{PX} 1 \mathrm{~N}_{-} \mathrm{X} 1 \mathrm{~N}_{-} \mathrm{U}$ & $\begin{array}{l}\text { AAGTACGATCTCTTGGATCAGA- } \\
\text { CAAGGACA }\end{array}$ \\
\hline 30 & $\mathrm{PYO}_{-} \mathrm{YO}_{-} \mathrm{U}_{-}$ & $\begin{array}{l}\text { TTACCCTTCACATAGGTGACGA- } \\
\text { CAAGGACA }\end{array}$ \\
\hline 31 & $\mathrm{PYON}_{-} \mathrm{YON}_{-} \mathrm{U}$ & $\begin{array}{l}\text { CACGTTTCTACAACCTGATAGA- } \\
\text { CAAGGACA }\end{array}$ \\
\hline 32 & $\mathrm{PY} 1_{-} \mathrm{Y} 1_{-} \mathrm{U}$ & $\begin{array}{l}\text { TTCTGCTCTTTTCATAGCGAGA- } \\
\text { CAAGGACA }\end{array}$ \\
\hline 33 & PY $1 N_{-} Y 1 N_{-} U$ & $\begin{array}{l}\text { TATGTCGGAAGTTAGATGCTGA- } \\
\text { CAAGGACA }\end{array}$ \\
\hline 34 & $\begin{array}{l}\mathrm{ZO}_{-} \mathrm{XO}_{-} \\
-\mathrm{YON} \mathrm{N}_{-} \mathrm{U}\end{array}$ & $\begin{array}{l}\text { GGAGATCAAGCTCATACACTCAAC- } \\
\text { CTGATAGACAAGGACA }\end{array}$ \\
\hline 35 & $\begin{array}{c}\mathrm{ZO}{ }_{-}{ }_{-} \mathrm{XON} \mathrm{N}_{-} \mathrm{YO} \\
-{ }_{-} \mathrm{U}\end{array}$ & $\begin{array}{l}\text { GGAGATCAAGGCTGGTATGGCATAG- } \\
\text { GTGACGACAAGGACA }\end{array}$ \\
\hline 36 & $\begin{array}{c}\mathrm{ZON} \mathrm{XO}_{-} \mathrm{YO}^{\mathrm{YO}} \\
-_{-} \mathrm{U}\end{array}$ & $\begin{array}{l}\text { ACTACTTCCGCTCATACACTCATAG- } \\
\text { GTGACGACAAGGACA }\end{array}$ \\
\hline 37 & $\begin{array}{l}\mathrm{ZON}-\mathrm{XON}-\mathrm{YON} \\
-\mathrm{U}\end{array}$ & $\begin{array}{l}\text { ACTACTTCCGGCTGGTATGGCAAC- } \\
\text { CTGATAGACAAGGACA }\end{array}$ \\
\hline
\end{tabular}

Table 1 (Continued)

\begin{tabular}{|c|c|c|}
\hline & Name & Sequence \\
\hline 38 & $\mathrm{C} 1 \mathrm{~A}_{-} \mathrm{XO} \mathrm{O}_{-} \mathrm{YO} \mathrm{O}_{-} \mathrm{U}$ & $\begin{array}{l}\text { AGTGTTGTTCCTCATACACTCATAG- } \\
\text { GTGACGACAAGGACA }\end{array}$ \\
\hline 39 & $\mathrm{C} 1 \mathrm{AN} \mathrm{N}_{-} \mathrm{XON} \_\mathrm{U}$ & $\begin{array}{l}\text { GGTACACATTGCTGGTATGGGA- } \\
\text { CAAGGACA }\end{array}$ \\
\hline 40 & $\mathrm{C} 1 \mathrm{AN}+\mathrm{YON} \_\mathrm{U}$ & $\begin{array}{l}\text { GGTACACATTCAACCTGATAGA- } \\
\text { CAAGGACA }\end{array}$ \\
\hline 41 & $\begin{array}{l}\mathrm{Z} 1_{-}{ }_{-} \mathrm{X} 1_{-}-\mathrm{Y} 1 \mathrm{~N} \\
-\mathrm{C} 1 \mathrm{BN}\end{array}$ & $\begin{array}{l}\text { TAAGTATCCGAACGAAGCACGTTA- } \\
\text { GATGCTCTATGGCTTT }\end{array}$ \\
\hline 42 & $\begin{array}{l}\mathrm{Z} 1_{-}{ }_{-} \mathrm{X} 1 \mathrm{~N}_{-} \mathrm{Y} 1- \\
\quad-\mathrm{C} 1 \mathrm{BN}\end{array}$ & $\begin{array}{l}\text { TAAGTATCCGTCTTGGAT- } \\
\text { CATTCATAGCGACTATGGCTTT }\end{array}$ \\
\hline 43 & $\begin{array}{l}\mathrm{Z} 1_{-} \mathrm{X}_{-} 1_{-} \mathrm{Y} 1_{-} \\
\quad-\mathrm{C} 1 \mathrm{~B}\end{array}$ & $\begin{array}{l}\text { TAAGTATCCGAACGAAG- } \\
\text { CACTTCATAGCGAGTTGTGAGTA }\end{array}$ \\
\hline 44 & $\begin{array}{l}\mathrm{Z1} 1_{-} \mathrm{X} 1 \mathrm{~N}_{-} \mathrm{Y} 1 \mathrm{~N} \\
\quad-\mathrm{C} 1 \mathrm{~B}\end{array}$ & $\begin{array}{l}\text { TAAGTATCCGTCTTGGATCAGTTA- } \\
\text { GATGCTGTTGTGAGTA }\end{array}$ \\
\hline 45 & $\begin{array}{c}\mathrm{Z} 1 \mathrm{~N}_{-} \mathrm{X} 1_{-}-\mathrm{Y} 1_{-} \\
-\mathrm{C} 1 \mathrm{BN}\end{array}$ & $\begin{array}{l}\text { CTAGTGGAAAAACGAAG- } \\
\text { CACTTCATAGCGACTATGGCTTT }\end{array}$ \\
\hline 46 & $\begin{array}{c}\mathrm{Z} 1 \mathrm{~N}_{-} \mathrm{X} 1 \mathrm{~N}_{-} \mathrm{Y} 1 \mathrm{~N} \\
-\mathrm{C} 1 \mathrm{BN}\end{array}$ & $\begin{array}{l}\text { CTAGTGGAAATCTTGGATCAGTTA- } \\
\text { GATGCTCTATGGCTTT }\end{array}$ \\
\hline 47 & $\begin{array}{l}\mathrm{Z} 1 \mathrm{~N}_{-} \mathrm{X} 1_{-}-\mathrm{Y} 1 \mathrm{~N} \\
-\mathrm{C} 1 \mathrm{~B}\end{array}$ & $\begin{array}{l}\text { CTAGTGGAAAAACGAAGCACGTTA- } \\
\text { GATGCTGTTGTGAGTA }\end{array}$ \\
\hline 48 & $\begin{array}{c}\mathrm{Z} 1 \mathrm{~N}_{-} \mathrm{X} 1 \mathrm{~N}_{-} \mathrm{Y} 1_{-} \\
-\mathrm{C} 1 \mathrm{~B}\end{array}$ & $\begin{array}{l}\text { CTAGTGGAAATCTTGGAT- } \\
\text { CATTCATAGCGAGTTGTGAGTA }\end{array}$ \\
\hline 49 & $\begin{array}{l}\mathrm{Z} 2_{-}-\mathrm{X} 1_{-}-\mathrm{Y}_{-} \\
\quad-\mathrm{U}\end{array}$ & $\begin{array}{l}\text { TCAACAGATCAACGAAG- } \\
\text { CACTTCATAGCGAGACAAGGACA }\end{array}$ \\
\hline 50 & $\mathrm{Z} 2 \mathrm{~N}_{-} \mathrm{X} 1 \mathrm{~N}_{-} \mathrm{Y} 1 \mathrm{~N}_{-} \mathrm{C}$ & $\begin{array}{l}\text { UTAGGATAGGCTCTTGGATCAGTTA- } \\
\text { GATGCTGACAAGGACA }\end{array}$ \\
\hline 51 & $\mathrm{Z} 2_{-} \mathrm{Y}{ }_{-} \mathrm{C} 1 \mathrm{~B}$ & $\begin{array}{l}\text { TCAACAGATCTTCATAGCGAGTTGT- } \\
\text { GAGTA }\end{array}$ \\
\hline 52 & $\mathrm{Z} 2_{-} \mathrm{X} 1_{-} \mathrm{C} 1 \mathrm{~B}$ & $\begin{array}{l}\text { TCAACAGATCAACGAAGCACGTTGT- } \\
\text { GAGTA }\end{array}$ \\
\hline 53 & $\mathrm{Z} 2 \mathrm{~N}_{-} \mathrm{X} 1 \mathrm{~N}_{-} \mathrm{C} 1 \mathrm{BN}$ & $\begin{array}{l}\text { TAGGATAGGCTCTTGGATCACTATG- } \\
\text { GCTTT }\end{array}$ \\
\hline 54 & $\mathrm{Z} 2 \mathrm{~N}_{-} \mathrm{Y} 1 \mathrm{~N}_{-} \mathrm{C} 1 \mathrm{BN}$ & $\begin{array}{l}\text { TAGGATAGGCGTTAGATGCTCTATG- } \\
\text { GCTTT }\end{array}$ \\
\hline
\end{tabular}

strands for $z 0$ are 56 nucleotides long. Examples of such strands are $\mathrm{z} 0 \mathrm{n}-\mathrm{x} 0-\mathrm{y} 0-\mathrm{u}$ and $\mathrm{z} 0-$ $\mathrm{x} 0-\mathrm{y} 0 \mathrm{n}-\mathrm{u}$. Note that the readout bands appear bright under both illumination conditions indicating that the bands consist of DNA strands possessing both Texas-red and fluorescein labels. All the bands appearing in Fig. 2 that are shorter than the readout bands are accounted for as incompletely assembled strands. Examples of such strands are: $u$ which is 13 nucleotides long, clan-c1bn which is 20 nucleotides long, $\mathrm{px} 0$ 


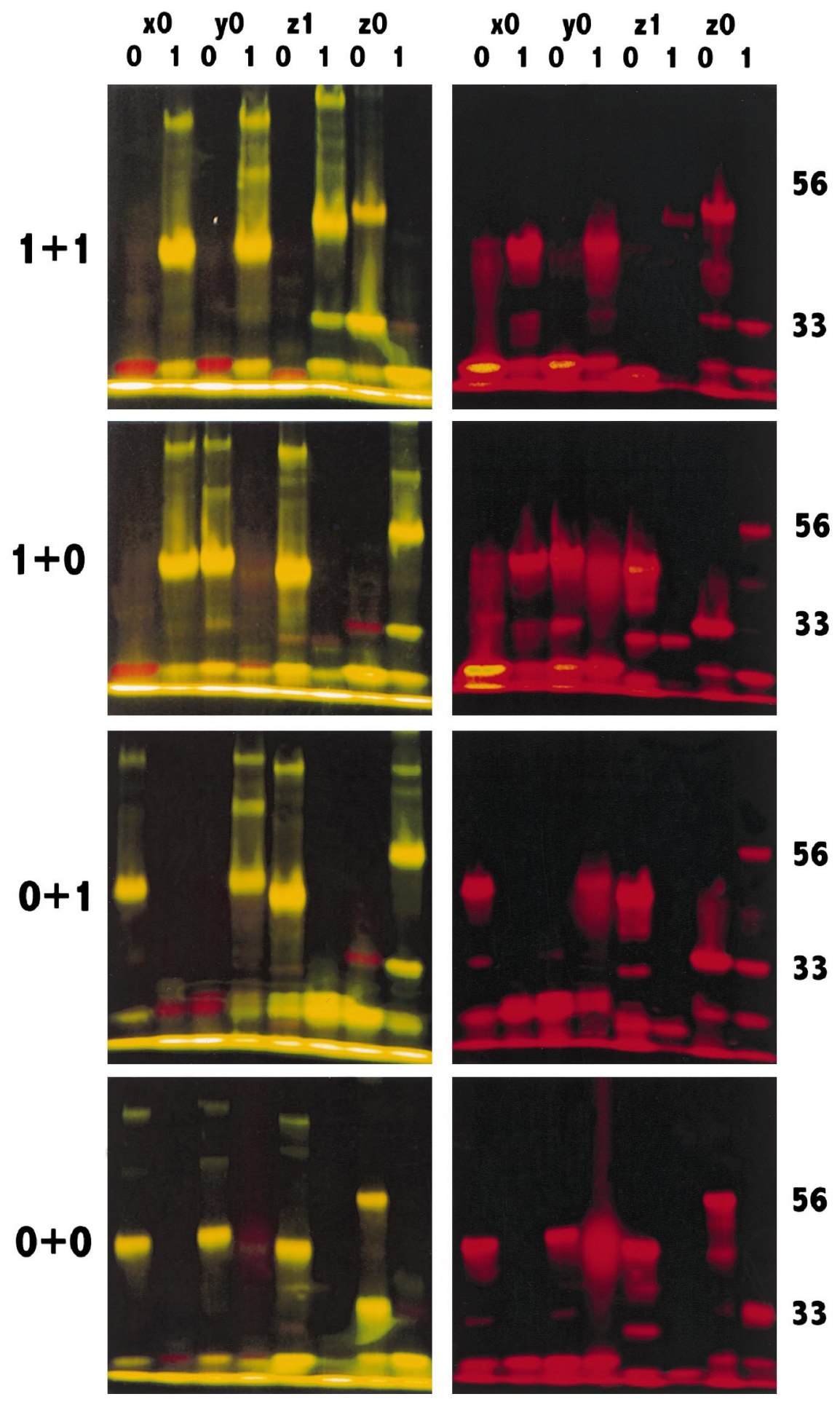

Fig. 2. 
and $\mathrm{x} 0-\mathrm{u}$ which are both 23 nucleotides long, $\mathrm{c} 1 \mathrm{an}-\mathrm{c} 1 \mathrm{bn}-\mathrm{x} 0$ which is 30 nucleotides long, and py $0-y 0$ which is 33 nucleotides long. The faint bands longer than the readout bands we attribute to faulty ligation. Note that these bands do not fluoresce in the red. Bands fluorescing only in the red appear at the same level at which the $x 0$ and $y 0$ readout bands appear. These we also attribute to faulty ligation.

The two-bit adder has not been exhaustively tested for all 16 possible inputs. Fig. 3 shows the results for $2+1,3+1$, and $3+3$. Displayed in this figure are the three pairs of gel columns for the bits of the sum $z$ arranged from left to right with the most significant bit first: $z 2, z 1$, and $z 0$. Again the value of the Boolean variable is determined by which lane of the pair has the highest band fluorescing in both the green and the red. The readout bands have been marked with white wedges. The readout bands for $z 0$ are 56 nucleotides long. For the $2+1$ case the strand is $\mathrm{z} 0-\mathrm{x} 0 \mathrm{n}-\mathrm{y} 0-\mathrm{u}$ appearing in column 1 . For the $3+1$ case the band is $\mathrm{z} 0 \mathrm{n}-\mathrm{x} 0-\mathrm{y} 0-\mathrm{u}$ appearing in column 0 . The readout bands for $z 1$ are 86 nucleotides long for the $2+1$ case and 96 nucleotides long for the $3+1$ and $3+3$ case. The strands for these three cases are respectively: $\quad \mathrm{z} 1-\mathrm{x} 1-\mathrm{y} 1 \mathrm{n}-\mathrm{c} 1 \mathrm{an}-\mathrm{c} 1 \mathrm{bn}-$ $\mathrm{x} 0 \mathrm{n}-\mathrm{u}, \quad \mathrm{x} 1-\mathrm{x} 1-\mathrm{y} 1 \mathrm{n}-\mathrm{c} 1 \mathrm{a}-\mathrm{c} 1 \mathrm{~b}-\mathrm{x} 0-$ $\mathrm{y} 0-\mathrm{u}$, and $\mathrm{z} 1-\mathrm{x} 1-\mathrm{y} 1-\mathrm{c} 1 \mathrm{a}-\mathrm{c} 1 \mathrm{~b}-\mathrm{x} 0-$ $\mathrm{y} 0-\mathrm{u}$. The readout bands for $z 2$ are 76 nucleotides long for the $2+1$ case and 86 nucleotides long for the $3+1$ and $3+3$ cases. For the $2+1$ and $3+1$ cases the $z 2$ readout strands are respectively: $\mathrm{z} 2 \mathrm{n}-\mathrm{y} 1 \mathrm{n}-\mathrm{c} 1 \mathrm{an}-\mathrm{c} 1 \mathrm{bn}-\mathrm{x} 0 \mathrm{n}-\mathrm{u}$ and $\mathrm{z} 2-$ $\mathrm{x} 1-\mathrm{c} 1 \mathrm{a}-\mathrm{c} 1 \mathrm{~b}-\mathrm{z} 0-\mathrm{y} 0-\mathrm{u}$. The $\mathrm{z} 2$ readout band for the $3+3$ case consists of a mixture of two strands of equal length: $z 2-x 1-c 1 a-c 1 b-$ $\mathrm{x} 0-\mathrm{y} 0-\mathrm{u}$ and $\mathrm{z} 2-\mathrm{y} 1-\mathrm{cla}-\mathrm{clb}-\mathrm{x} 0-$ $\mathrm{y} 0-\mathrm{u}$. The illumination conditions are the same as those described for the half adder case. Because there are more bands due to imperfect starting
DNA oligomers and incomplete by-products of the computation, the lanes become cluttered with bands. The identification of the readout bands is thus facilitated by using both length and color discrimination. The readout bands are again the highest bands which fluoresce in both the green and the red. In an embodiment in which the Texas-red labeled strands are attached at spots on a hybridization plate these extraneous products should wash away giving a readout of the results of the computation that is free of background. The bands below the readout bands are attributed to incomplete assembly products which occur with nucleotide lengths of $13,23,33,43,53$, and 63 . The bands above the readout bands are attributed to faulty ligation. Note that these bands are not visible in the photographs taken with the red filter.

The speed of the addition algorithm is partly limited by the rate of forming duplex DNA from the single stranded DNA of the operators and variables. Suppose we have a type of DNA that contains $T$ base pairs and has been cut up into small and unique pieces. Let $C_{0}$ be the total concentration of nucleotides (i.e., DNA bases) in solution. If the DNA has been denatured (i.e., is single stranded) and rehybridization conditions commence at time $t=0$, the fraction of strands remaining single after time $t$ is (Cantor and Schimmel, 1980)

$f_{\mathrm{s}}(t)=(1+t / \tau)^{-1}$

where $\tau^{-1}=C_{0} k_{2} / 2 T$. The rate of reassociation of DNA is optimal for sodium ion concentrations of order $0.2 \mathrm{M}$ and temperatures $\sim 25^{\circ} \mathrm{C}$ below the melting point of the DNA (Marmur et al., 1963). For DNA segments less than a few hundred bases in length, for which one does not have to consider excluded volume effects (Wetmur and Davidson, 1968), the second-order rate constant is then approximately (Britten and Kohne, 1968) $k_{2} \approx$ $1.0 \times 10^{6} 1 \mathrm{~mol}^{-1} \mathrm{~s}^{-1}$. The 54 oligomers for the addition algorithm contain $\sim 1500$ bases, so we

Fig. 2. Electrophoresis results for the half adder. The photos on the left are taken with blue light illumination to selectively excite the fluorescein which fluoresces in the green. The photos on the right are taken with green light illumination to selectively excite the Texas-red and a red filter was used in front of the camera. The additions performed are indicated by the labels on the left. The Boolean variables represented by the lanes are indicated at the top of the figure. Each Boolean variable is represented by two lanes labeled 0 and 1 . The truth value of the variable is determined by which of the pair of lanes has the highest bright band fluorescing in both the green and the red. The number of nucleotides possessed by the oligomers of some of the bands is indicated on the right. 


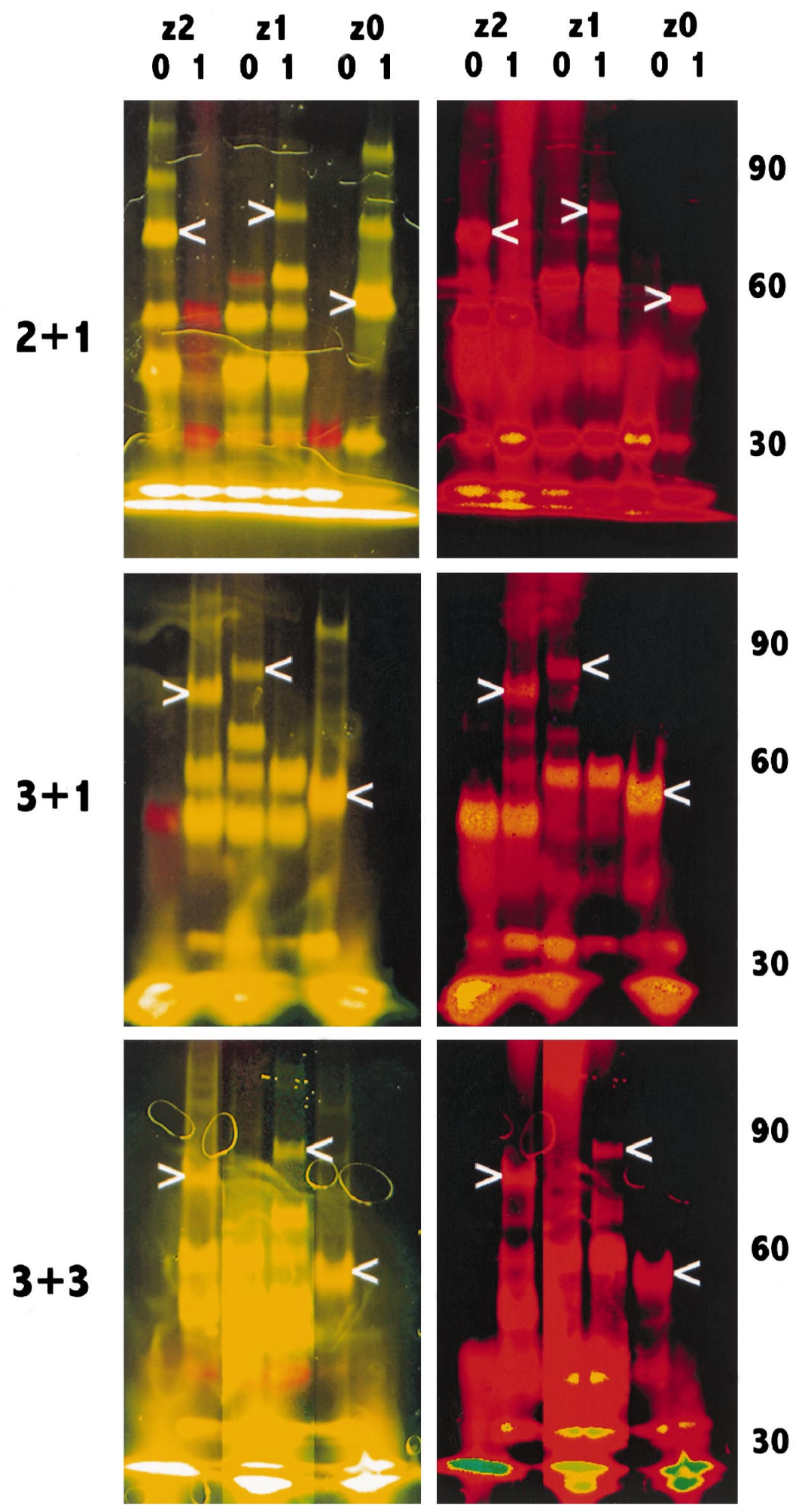

Fig. 3. 
could think of them as being parts of a DNA duplex with $T=750$. Assuming the oligomers are present at a concentration of $100 \mu \mathrm{M}$, the concentration of bases is $C_{0} \approx 1 \mathrm{mM}$. Ignoring the effects of repeated sequences, we have $\tau \approx 3 \mathrm{~s}$. While this seems to be slow compared to electronic integrated circuits, at the stated concentration there are $\sim 40$ copies of the algorithm in a volume of 1 $\mu \mathrm{m}^{3}$. In a $1 \mathrm{ml}$ volume, the computations would be happening at a total rate of $10^{13} \mathrm{~s}^{-1}$. This large rate might be converted into the useful parallelism envisioned by Adleman (1994) by partitioning the reaction vessel into separate $1 \mu \mathrm{m}^{3}$ active volumes (Rambidi et al., 1992) in which parallel reactions would be taking place.

We have described a method for implementing Boolean logic in DNA and have illustrated this by devising a two-bit adder. We have successfully, although not exhaustively, tested the two-bit adder. The half adder subunit, however, has been successfully tested for all possible inputs. We argue that for this method of DNA computation to be competitive with electronic computation the reaction vessel would have to be partitioned into separate active volumes to exploit the massive parallelism that DNA computing potentially offers.

\section{Methods}

For the experiments reported here oligonucleotides 11-24 were Texas-red labeled on the $3^{\prime}$ end to facilitate band identification during gel electrophoresis. The oligonucleotides including the fluorescent dye labels were manufactured and desalted by Genosys Biotechnologies, Inc. The oligonucleotides were used without further purification. The DNA was diluted in TE buffer (10 $\mathrm{mM}$ Tris, $1 \mathrm{mM}$ EDTA) to a standard concentration of 3 or $0.2 \mathrm{mM}$ as indicated below. These are the DNA stock solutions. T4 DNA ligase (400 000 units $\mathrm{ml}^{-1}$ ) and T4 Polynucleotide kinase (10 000 units $\mathrm{ml}^{-1}$ ) were purchased from New England Biolabs.

The protocol for sum readout is now given: Solutions of the input DNA $x 0, x 0 n, x 1, x 1 n$, $\mathrm{y} 0, \mathrm{y} 0 \mathrm{n}, \mathrm{y} 1, \mathrm{y} 1 \mathrm{n}$ and the fluorescent indicator DNA $u$ are prepared at $3 \mathrm{mM}$ concentration. All other DNA stock solutions are prepared at 0.2 $\mathrm{mM}$ concentration. The Input solution, consisting of $30 \mu \mathrm{l}$ of $10 \times$ T4 DNA ligase buffer plus 1 $\mu l$ of each of the four inputs, is prepared. For example, if $x=3$ and $y=1$ are the two numbers to be added, then the inputs used would be $x 1$, $\mathrm{x} 0, \mathrm{y} 1 \mathrm{n}$, and y0. $5 \mu \mathrm{l}$ of this solution is placed into each of six vials labeled $z 2 n, z 2, z 1 n, z 1, z 0 n$, and $z 0$. To each of these are added respectively 2 $\mu 1$ of the solutions of $3^{\prime}$ Texas-red labeled oligonucleotides $z 2 n, z 2, z 1 n, z 1, z 0 n$, and $z 0$. To vials $z 2 n, z 1 n$, and $z 1$ are added $2 \mu 1$ of the c1an-c1bn solution. To vials $z 2, z 1 n$, and $z 1$ are added $2 \mu \mathrm{l}$ of the $\mathrm{c} 1 \mathrm{a}-\mathrm{c} 1 \mathrm{~b}$ solution. To the six vials $z 2 n-z 01 \mu$ of T4 Polynucleotide kinase is added and the contents of each vial is mixed. The vials are left to incubate at room temperature for $30 \mathrm{~min}$. The vials are then heated to above $65^{\circ} \mathrm{C}$ for $20 \mathrm{~min}$ to inactivate the kinase. The solution $\mathrm{u} 2$ consisting of $30 \mu \mathrm{l}$ of $10 \times \mathrm{T} 4$ DNA ligase buffer and $1 \mu \mathrm{l}$ of the $\mathrm{u} 1$ solution is prepared. $5 \mu \mathrm{l}$ of this solution is placed into each of the six vials. To the vial $z 2 n 1 \mu$ of each of the following operator oligonucleotides is added: $\mathrm{Z} 2 \mathrm{~N}_{-} \mathrm{X} 1 \mathrm{~N}_{-} \mathrm{Y} 1 \mathrm{~N}_{-} \mathrm{U}, \mathrm{Z} 2 \mathrm{~N}_{-} \mathrm{X} 1 \mathrm{~N}_{-} \mathrm{C} 1 \mathrm{BN}, \quad \mathrm{Z} 2 \mathrm{~N}_{-}$ $Y 1 N_{-} C 1 B N_{,} C 1 A N_{-} X O N_{-} U$, and $C 1 A N_{-} Y O N_{-} U$. To vial $z 21 \mu$ of each the following operator oligonucleotides is added: $\mathrm{Z} 2_{-} \mathrm{X} 1_{-} \mathrm{Y} 1_{-} \mathrm{U}, \mathrm{Z} 2_{-}$ $\mathrm{Y} 1_{-} \mathrm{C} 1 \mathrm{~B}, \mathrm{Z2} 2_{-} \mathrm{X} 1_{-} \mathrm{C} 1 \mathrm{~B}$, and $\mathrm{C} 1 \mathrm{~A}_{-} \mathrm{XO} \mathrm{Y}_{-} \mathrm{YO} \mathrm{U}$. To vial $z \ln 1 \mu 1$ of each of the following operator oligonucleotides is added: $\mathrm{Z} 1 \mathrm{~N}_{-} \mathrm{X} 1_{-} \mathrm{Y} 1 \mathrm{~N}_{-} \mathrm{C} 1 \mathrm{~B}$, $\mathrm{ZlN} \mathrm{X}_{-} \mathrm{N}_{-} \mathrm{YI} \mathrm{I}_{-} \mathrm{C} 1 \mathrm{~B}, \quad \mathrm{ZlN} \mathrm{N}_{-} \mathrm{I}_{-} \mathrm{YI} \mathrm{I}_{-} \mathrm{C} 1 \mathrm{BN}$, $\mathrm{Z} 1 \mathrm{~N}_{-} \mathrm{X} 1 \mathrm{~N}_{-} \mathrm{Y} 1 \mathrm{~N}_{-} \mathrm{C} 1 \mathrm{BN}, \mathrm{C} 1 \mathrm{~A}_{-} \mathrm{XO} \mathrm{Y}_{-} \mathrm{YO} \mathrm{U}_{-}$, C $1 A_{-} \mathrm{XON}_{-} \mathrm{U}$, and CIAN_YON_U. To vial $z 11$ $\mu \mathrm{l}$ of each of the following operator oligonucle-

Fig. 3. Gel electrophoresis results for the two-bit adder performing the additions $2+1,3+1$, and $3+3$ as indicated by the labels on the left. The Boolean variables represented by the lanes are indicated at the top of the figure. Each Boolean variable is represented by two lanes labeled 0 and 1 . The readout bands are identified with white arrows. Note that for the $3+3$ case the three pairs of lanes for $z 0, z 1$, and $z 2$ were separately processed for optimum contrast. The numbers on the right provide a scale for the length of the oligomers in terms of the number of nucleotides. 
otides is added: $\mathrm{Z} 1_{-} \mathrm{XI}-\mathrm{Y} I \mathrm{~N}_{-} \mathrm{ClBN}, \mathrm{Z} 1_{-} \mathrm{X} 1 \mathrm{~N}_{-}$

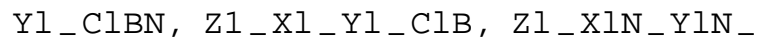
$\mathrm{ClB}, \mathrm{ClA} \mathrm{XO}_{-} \mathrm{YO} \mathrm{U}_{-}, \mathrm{C} 1 \mathrm{AN} \mathrm{XON}_{-} \mathrm{U}$, and CIAN_YON_U. To vial $z 0 n 1 \mu \mathrm{l}$ of each of the following operator oligonucleotides is added: $\mathrm{ZON} \_\mathrm{XO} \_\mathrm{YO} \_\mathrm{U}$ and $\mathrm{ZON} \mathrm{N}_{-} \mathrm{XON}_{-} \mathrm{YON}_{-} \mathrm{U}$. To vial $z 01 \mu \mathrm{l}$ of each of the following operator oligonucleotides is added: $\mathrm{ZO}_{-} \mathrm{XO}_{-} \mathrm{YON}-\mathrm{U}$ and $\mathrm{ZO}$ $\mathrm{XON} \mathrm{N}_{-} \mathrm{Y}_{-} \mathrm{U}$. To each of the six vials $2 \mu 1$ of $\mathrm{T} 4$ DNA ligase is added and the contents of each vial again is mixed. The vials are incubated at room temperature for $30 \mathrm{~min}$ then heated to $65^{\circ} \mathrm{C}$ for 10 min to inactivate the ligase. To each vial $10 \mu \mathrm{l}$ of stop mix consisting of a $30 \%$ solution of FICOLL (Sigma) with $250 \mathrm{mM}$ EDTA (Sigma) were added in preparation for gel electrophoresis.

The protocol for the input readout is similar to the above protocol except now one employs eight vials labeled $p x 1 n, p x 1, p x 0 n, p x 0, p y 1 n, p y 1$, py $0 n$, and $p y 0$, each containing the corresponding Texas-red labeled nucleotide from rows 17-24 of Table 1. Now, only the operator strands 26-33 are used, each in its corresponding vial. Because the number of strands that hybridize is reduced, the DNA, ligase, and buffer concentrations can be reduced. In particular, all the DNA stock solutions were prepared at $0.2 \mathrm{mM}$ concentration. For the case of $3+1$ addition, the solution Input consisted of $80 \mu 12 \times$ T4 ligase buffer, $16 \mu \mathrm{l}$ each of $\mathrm{x} 1, \mathrm{x} 0, \mathrm{y} 1 \mathrm{n}$, and $\mathrm{y} 0 . \mathrm{u} 2$ now consists of $40 \mu 1$ $2 \times$ T4 ligase buffer and $8 \mu \mathrm{lu} 1.1 \mu \mathrm{l}$ of T4 DNA ligase was used in each vial rather than $2 \mu$ l. These reduced concentrations were also employed for both the input readout and the output readout for the half adder. Also for the half adder experiments, instead of employing $z 1 n$ and $z 1$, the transfer strands 9 and 10, Texas-red labeled at the 3 ' end, were employed as the carry bit readout.

Gel electrophoresis was performed on the contents of each vial. Precast mini-polyacrylamide gels (10-27\% gradient gel in a glass cassette, Sigma, catalog number P-3216) were used for the electrophoresis. The electrophoresis was performed at a temperature of $90^{\circ} \mathrm{C}$ to denature the DNA. Fluorescence photography using a Kodak DC 120 CCD camera was employed to record the results of gel electrophoresis. For fluorescence photography, the glass cassettes were edge illuminated. A $1 \mathrm{~kW}$ Xe arc lamp serving as a white light source was used for illumination. The light was filtered at $450 \mathrm{~nm}$ (Rolyn Optics K45 Stock number 66.2105) to observe fluorescein fluorescence and an ethidium bromide photography filter was used in front of the camera lens. The $450 \mathrm{~nm}$ light also excites Texas-red fluorescence. To observe only the Texas-red fluorescence the source light was filtered in the green at $550 \mathrm{~nm}$ (Rolyn Optics stock number 66.2115) and a $650 \mathrm{~nm}$ filter (Rolyn Optics K55 stock number 66.2125) was used in front of the camera lens to block fluorescein fluorescence.

\section{References}

Adleman, L.M., 1994. Molecular computation of solutions to combinatorial problems. Science 266, 1021-1023.

Britten, R.J., Kohne, D.E., 1968. Repeated sequences in DNA. Science 161, 529-540.

Cantor, C.R., Schimmel, P.R., 1980. Biophysical Chemistry, Part III: the behavior of biological macromolecules, Freeman, New York, ISBN 07167-1191-5, pp. 1226-1234.

Guarnieri, F., Fliss, M., Bancroft, C., 1996. Making DNA add. Science 273, 220-223.

Lipton, R.J., 1995. DNA solution of hard computational problems. Science 268, 542-545.

Marmur, J., Rownd, R., Schildkraut, C.L., 1963. Prog. Nucleic Acid Res. 1, 231-300.

Ouyang, Q., Kaplan, P.D., Liu, S., Libchaber, A., 1997. DNA solution of the maximal clique problem. Science 278, 446449.

Rambidi, N.G., Chernavskii, D.S., Krinsky, V.I., 1992. Information processing and computing devices based on biomolecular nonlinear dynamic systems. In: Kristof Sienicki (Ed.), Molecular Electronics and Molecular Electronic Devices, Vol. 1, CRC Press, Boca Raton, ISBN 0-8493-8061-8, p. 85.

Wetmur, J.G., Davidson, N., 1968. Kinetics of renaturization of DNA. J. Mol. Biol. 31, 349-369. 